Inside this issue

President's Message ........................2

Co-editors' Messages........................3

Notes from the Editor Emeritus:

Bernard Nusbaum, MD.

Lowering the female hairline: two treatment options

Meetings and Studies: Review of the $20^{\text {th }}$ ASM of the ISHRS ..........17

Message from the 2013 ASM

Program Chair.

SAC: The value of attending the annual surgical assistants program.

Message from the 2013 ASM Surgical Assistants

Program Chair

ISHRS Annual Giving Fund

2012 year-end report

Classified Ads.

CALL FOR ABSTRACTS Deadline: March 1, 2013

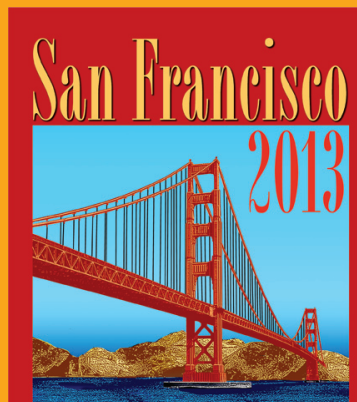

ISHRS 21 ${ }^{\text {ST }}$ ANNUAL SCIENJIJIC MEEIING October 23-26 Hyate Regengy San Fransiseg

\title{
A review of cellular biopreservation considerations during hair transplantation
}

Aby J. Mathew, PhD Bothell, Washington, USA amathew@biolifesolutions.com

\section{Introduction}

Appropriate clinical biopreservation of cells and tissues is a critical factor in hair transplantation procedures, as well as in regenerative medicine (cell therapies and tissue engineering) and organ preservation. During the course of a hair transplantation procedure, the cells and/or tissues experience multiple forms of stresses related to the procedure from before the donor strip and/or follicular units are extracted, through the dissection and graft holding stages, and past the point of re-implantation. There are certain cellular and biochemical aspects of the hair transplant model that are unique to the specific types of cells and tissues involved. However, there is also much that can be taken into consideration from other in vitro and clinical cell models relevant to regenerative medicine, as well as from existing organ/tissue preservation knowledge.

Under normal conditions, the environment of human cells and tissues consists of an isotonic osmotic balance of ions that is maintained by ATP-driven cell membrane pumps. Major ionic constituents include sodium, potassium, calcium, and magnesium — each regulated by membrane pumps/channels that, along with chloride, are actively pumped inside or outside the cell to counterbalance the osmotic pressure of non-permeable fixed molecules inside the cell and subsequently regulate the passive flow of water into and out of the cells. In this manner, although highly simplified, there is an intracellular milieu and an extracellular milieu that are distinctly different from one another. Under normothermic conditions $\left(37^{\circ} \mathrm{C}\right.$, appropriate balance of oxygen/carbon dioxide, exchange of nutrients/wastes, etc.), the fluid bathing the cells and tissues is isotonic, or also referred to as extracellular-like. The normothermic flow of nutrients through the cellular metabolic pathways fuels the production of ATP (adenosine triphosphate) that, in turn, drives the membrane ion pumps to maintain the osmotic balance. Cellular waste products are expunged from the cells, and free radicals generated by normal metabolism are removed from potential negative impact by the cell's antioxidant mechanisms. Only once these basic cell processes for maintaining "life" are in working order can the cell's energies be directed to further functional cellular processes specific to that cell's "job."

When cells, tissues, and organs are disconnected from this "normal" set of conditions even for a short time, there are many potential unbalanced states leading to detrimental consequences. Absence of nutrients (glucose, oxygen, etc.) deprives the cells of the raw fuel components needed to generate the cell's refined fuel, ATP. Short-term interruptions to the cell energy cycle can be compensated with derivation of cellular energy via the lactic acid cycle but cannot be maintained indefinitely. However, it is important to appreciate that the overall cell machinery is a highly complex engine of parts and pathways that generates intermediate compounds from specialized reactions at specific steps, and that there are aspects of this cellular engineering that cannot currently be artificially replicated in the laboratory or by cell culture media. Furthermore, it is also important to remember the critical functions of waste removal and gas exchange, which often require specialized laboratory equipment to effectively compensate in the absence of the natural cellular mechanisms. Therefore, current attempts to replicate out-of-body normothermic conditions have the potential to be incomplete and suboptimal.

\section{Cellular and Molecular Considerations for Biopreservation}

Biopreservation can be described as processes that suppress degradation of biologics for the post-preservation recovery of structure, viability, and function. ${ }^{1,2}$ Hypothermic storage (primarily $2^{\circ}-8^{\circ} \mathrm{C}$ ) has been the preferred practical mechanism for storing cells, tissues, and organs for short periods of time (such as applicable in typical hair transplantation procedures). The ability of hypothermia to suppress metabolism is the key to maintaining cells, tissues, and organs under ischemic conditions. ${ }^{3}$ The beneficial properties of hypothermia have been appreciated for a number of years. For example, in 1939, surface cooling of ischemic limbs was found to confer preservation ability for rat limb survival. ${ }^{4}$ In the 1950s, hypothermia played an important role in the development of cardiopulmonary bypass surgery, ${ }^{5,6}$ and in 1969 the demonstration that cold storage was an effective means of kidney preservation ${ }^{7}$ stimulated the development of cold storage solutions for the purpose of organ preservation. Ambient 
Cellular biopreservation

from front page

storage results in limited reduction of metabolic demands (cells/ tissues) and higher rates of enzymatic and/or structural decay (cells/tissues, blood, plasma, proteins, nucleic acids). Refrigerated/hypothermic $\left(2^{\circ}-8^{\circ} \mathrm{C}\right)$ storage allows for greater reduction in degradation related to ischemia/hypoxia and enzymatic decay, based on the $\mathrm{Q}_{10}$ equation principle that most metabolic reactions will slow down approximately $50 \%$ for every $10^{\circ} \mathrm{C}$ decline in temperature from normothermic conditions. ${ }^{3}$ However, the protective conditions of hypothermia may also introduce potential stresses. The same characteristics of hypothermia that confer protection for cells/tissues (reduced metabolic demand) result in inactivation of ATP-driven ion pumps that would normally maintain osmotic balance, membrane phase changes, organelle instability, free radical generation, water flux, and ultimately, the accumulation of stresses that may cause cell death via apoptosis, necrosis, and/or secondary necrosis. ${ }^{8-21}$ These conditions are exacerbated by storage/holding media that typically consist of culture media or saline. Culture media and saline are osmotically characterized as isotonic/extracellular-like solutions; that is, their ionic balance is similar to normothermic extracellular fluid. While suited for maintenance of cells at normothermic temperature $\left(37^{\circ} \mathrm{C}\right)$ in cell culture conditions that mimic native environments, these extracellular-like solutions do not balance the hyperosmotic cells during low temperature preservation, and hence amplify the preservation-induced stress for cells and tissues since both the cells and the extracellular-like holding solutions lack active and passive mechanisms for modulating the hyperosmotic state.

From the moment that a biospecimen (such as a hair transplant donor strip and grafts of follicular units) is obtained by removal from the native environment, a degradation process begins and stresses accumulate. Ex vivo hypothermic conditions are utilized as a first step for slowing the rate of degradation of grafts. Under normal conditions in vivo, cells are bathed in an extracellular medium that is high in sodium and low in potassium compared to the interior of the cell. Plasma membrane ion pumps, such as the $\mathrm{Na}^{+}-\mathrm{K}^{+}$ATPase that maintains the sodium and potassium gradients, use much of the energy produced from oxidative phosphorylation. For example, the maintenance of the $\mathrm{Na}^{+}, \mathrm{K}^{+}$, $\mathrm{H}^{+}$, and $\mathrm{Ca}^{+2}$ ion concentrations in nerve and kidney cells account for as much as $25 \%$ of the ATP utilized, and as much as $50 \%$ of available ATP is used in erythrocytes for ion balance. ${ }^{22}$ As mentioned previously, the maintenance of the levels of key ions outside the cell counteracts the osmotic pressure resulting from intracellular proteins, macromolecules, and organelles. ${ }^{23}$ Anaerobic hypothermia, which is inevitable during standard ex vivo strip/graft storage intervals, results in decreased ATP production and suppressed activity of the ion pumps, ${ }^{24}$ even as hypothermic storage provides the benefits of decreased metabolic rate and reduced demand for ATP. As a result of hypothermia in the absence of an optimized preservation solution (such as when cells are in isotonic saline solutions), many ions diffuse along their gradients into and out of the cell. Consequently, there is often cellular swelling because of water movement into the cell that may ultimately result in cellular lysis. ${ }^{25}$

Glycolysis for energy production continues under hypothermic conditions, although at a highly reduced level. Glycolysis is blocked at several points due to the inactivation of regulatory enzymes such as glycogen phosphorylase and glyceraldehyde3 -phosphate dehydrogenase. ${ }^{26}$ In addition, the enzymes of the citric acid cycle are known to undergo conformational changes as a result of hypothermia (pyruvate kinase, glutamate dehydrogenase, arginosuccinase). Due to low-level glycolytic activity and disruption of the citric acid cycle and oxidative phosphorylation, lactic acid production results, as well as generation of hydrogen ions. The resulting intracellular acidosis (and tissue acidosis) causes lysosomal instability and cellular degradation. ${ }^{27}$

Considering the multiple steps of a hair transplantation procedure, there are a number of points where the tissue and cells might be negatively affected due to stress factors. Prior to excision, epinephrine at the donor site causes anoxia. The donor strip, or follicular units, is physically extracted from native tissue. This interferes with nutrient/waste exchange from the normal blood supply. Tissue and cells that are normally protected from the outer environment are now exposed to atmospheric $\mathrm{O}_{2} / \mathrm{CO}_{2}$, different temperatures, and potential airborne pathogens. The cells and tissue would begin a degradation process, but this may be somewhat slowed temporarily by placing the tissues into a hypothermic condition. According to surveys conducted by Cotterill/ISHRS, this usually is achieved by placing the strip and grafts into chilled normal saline. ${ }^{28}$ Some hair transplant physicians may utilize modified isotonic solutions such as Plasma-Lyte ${ }^{\circledR}$, Lactated Ringer's ${ }^{\circledR}$, DMEM, or William's E (although none of these isotonic-based solutions are utilized for effective cell/tissue biopreservation in other arenas such as regenerative medicine or organ preservation, and culture media such as DMEM/William's E may not fit the Quality/Regulatory footprint for clinical applications, especially if additives are utilized at point of care which represents a potential contamination risk). Slivers one to two follicular units thick are removed from the strip via microscopic dissection, which is often a period of warming due to the heat emitted from the microscope lamp. At this stage, slivers are often placed once again in chilled solution until they are again dissected under a microscope into individual follicular unit grafts. This periodic exchange between chilled storage and warming intervals can be a point of variable stress, especially depending on the number of grafts. Eventually, rewarming on the gloved hand of the physician pending placement varies from less than a minute to probably 5 to 8 minutes or more in some practices. ${ }^{29}$ Finally, healing of the graft and revascularization to support long term survival is another point of variability and stress; for example, transplanted hair follicles may require $\sim 3$ days for revascularization to replenish the new blood supply. ${ }^{30,31}$ During this entire process, there is also the potential for dehydration, transection, in-process blunt trauma, and ischemia reperfusion injury following implantation of the grafts. ${ }^{32,33}$ A review of these steps within the hair transplantation procedure offers approximately a dozen points of potential stress to the tissues and cells. Limmer reported the steady decline in graft viability in correlation with graft storage time, ${ }^{34}$ which was also reported by Kim and Hwang. ${ }^{35,36}$ Cooley demonstrated the extensive generation of potentially harmful free radicals following graft reimplantation. ${ }^{32}$ Krugugler reported the onset of DNA fragmentation, and the benefits of antioxidants within the storage solution. ${ }^{37,38}$ Parsley and Perez-Meza nicely reviewed a wide variety of considerations related to the topic of strip/graft storage..$^{33}$ Other cell models have shown that similar stresses result in a variety of molecular responses within the cell, even for short periods, sometimes in manners that are not visible with simple viability assessment methods. ${ }^{39,40}$ Any "stress" tends to elicit a response within the cell, with subsequent cell damage being dependent on whether the cell is able to "manage" the 


\section{Cellular biopreservation}

\section{from page 7}

stresses (similar to our own ability to manage the cumulative impact of personal and physical stresses). Cellular and molecular responses that can be triggered by the various potential stresses within a routine hair transplant procedure may involve biochemical perturbations, ${ }^{41-43}$ generation of cold shock proteins, ${ }^{44}$ change in cell volume ${ }^{45}$ which can also affect the cell membrane, protein uncoupling, ${ }^{46}$ unfolded protein response, ${ }^{47}$ and various mechanisms of cell death from suboptimal biopreservation ${ }^{11,13,48}$ and temperature variations ${ }^{49}$ that manifest at the genomic, proteomic, mitochondrial, membrane, and enzymatic levels of the cell, ${ }^{11,13,15,50-53}$ Simply, the more stresses on the cells and tissues, the less likelihood of cellular recovery and more likelihood of cell damage or death. Mechanisms of "buffering" or reducing the accumulation of stresses during the procedure would benefit graft recovery. (Note: We have not even touched on the impact of patient variability as a potential enhancer of cell stress yet; however, this is discussed below).

\section{Focus on the Preservation Solution for Graft Holding}

An effective cold storage solution utilized during the graft holding stage of hair transplantation requires components that will provide an optimal concentration of ions and impermeant molecules to maintain ionic and osmotic balance during hypothermic dysregulation of homeostasis. ${ }^{8}$ An intracellular-like solution, as opposed to an isotonic/extracellular-like solution such as culture media or saline, is one that closely balances the altered cellular ion concentrations that result from and at hypothermic temperatures and nutrient deprived conditions that exist when cells, tissues, or organs are without normal blood supply at normothermic conditions. Aside from the ionic concentrations in an optimized preservation solution designed to balance the ions of cells during hypothermia, there are several additional considerations that are important to hypothermic preservation. The solution should contain impermeant molecules replacing chloride ion $\left(\mathrm{Cl}^{-}\right)$in the extracellular space. The decreased activity of the $\mathrm{Na}^{+}$pump during hypothermia results in increased $\mathrm{Na}^{+}$levels within the cell, and subsequently results in increased $\mathrm{Cl}^{-}$levels within the cell to maintain the balance of charges. The increased osmotic pressure within the cell causes an influx of water from the extracellular fluid that induces cell swelling and lysis (in the absence of an appropriate preservation solution). Glucose may serve as a source of energy during cold storage. However, excess glucose during this metabolically depressed and oxygen deprived state will favor the production of lactic acid, resulting in cellular acidosis. ${ }^{54}$ Therefore, glucose should be present at very low levels. An effective buffer is also critical to the system. Normally, cells and tissues are buffered primarily by the bicarbonate buffer system. However, bicarbonate is not the most effective of buffers at low temperatures. ${ }^{42,43}$ Finally, upon recovery from cold storage, energy substrates can aid the synthesis of ATP for the increased metabolic demands of the cell. ${ }^{55}$ All of these considerations are important components of an optimized hypothermic preservation solution that is designed to maintain ionic and osmotic balance, prevent acidosis, and prevent cell swelling. With the evolution of optimized preservation media, the use of these solutions greatly advanced the field of organ transplantation, and this success has prompted the development and use of optimized preservation solutions for collection, storage, and transport of other biologic materials such as tissues and cells.
Traditional approaches to low temperature biopreservation often focused on the biophysical parameters of the system-ice management in frozen storage, cell volume, water content, etc. This approach laid a strong foundation for the science of preservation, and allowed for utilization of low temperature preservation as a tool for increasing the stability of cells and tissues. Further development of the science of biopreservation brought together the disciplines of cryobiology, cell biology, and molecular biology, as well as recognized that biopreservation methods involve many common stress pathways that result in biologically related mechanisms of cell death (apoptosis, necrosis, and secondary necrosis). This engineered approach for improved biopreservation (i.e., holding/storage) solutions for cells and tissues led to the development of the intracellularlike HypoThermosol ${ }^{\circledR}$ platform of low temperature preservation solutions that incorporates the discussion points mentioned previously such as balanced ions and impermeants, targeted $\mathrm{pH}$ buffering, potent free radical scavengers, and mitigation of apoptosis and necrosis. ${ }^{8-21,56}$

This improved biopreservation protocol of using an intracellular-like solution has been qualified by a number of regenerative medicine therapies including cardiac applications, ${ }^{57-58}$ stem cell applications,${ }^{59}$ and dermal fibroblast applications ${ }^{60}$ To personify the difference to the cell between isotonic solutions (normal saline, Plasma-Lyte, Lactated Ringer's) and an optimized intracellular-like solution (such as HypoThermosol ${ }^{\circledR}$-FRS), imagine being in Minnesota in the cold of winter; isotonic solutions (balanced for cells and tissues at $37^{\circ} \mathrm{C} / 98.6^{\circ} \mathrm{F}$ ) are like a tank top (saline) or T-shirt (Plasma-Lyte, Lactated Ringer's). A brief exposure to the cold may be uncomfortable, cause a cellular response such as the equivalent of "shivering," and may cause non-lethal damage. But wearing an insulated winter coat (optimized intracellular-like solution) makes the short exposure easier to bear, and is of more noticeable benefit with longer exposure to that cold exposure-or of more benefit to those (cells) more sensitive to the cold.

Figures 1 and 2 highlight the variability in preservation efficacy between an intracellular-like biopreservation solution and traditional isotonic storage media.

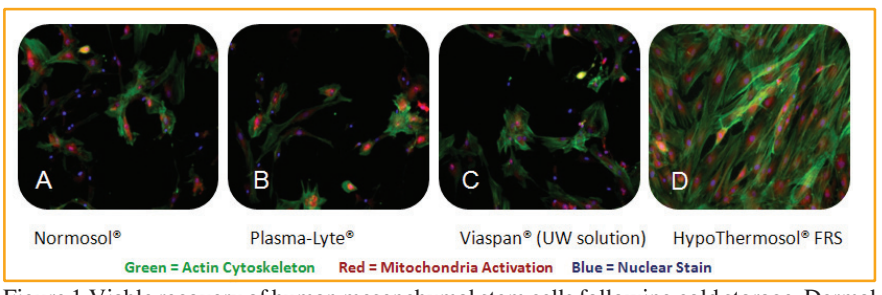

Figure 1.Viable recovery of human mesenchymal stem cells following cold storage. Dermal papilla cells share lineage with mesenchymal stem cells. Cell types relevant to hair transplant procedures, such as dermal fibroblasts and epithelial keratinocytes, also exhibit similar post-preservation results to the fluorescent micrographs above (fluorescent micrographs and data reference provided courtesy of BioLife Solutions, Inc.). Cells stored in Normosol (A), Plasma-Lyte (B), and Viaspan (C) exhibit lower cell number and less cell integrity following storage, in comparison to cells preserved in HypoThermosol-FRS (D).

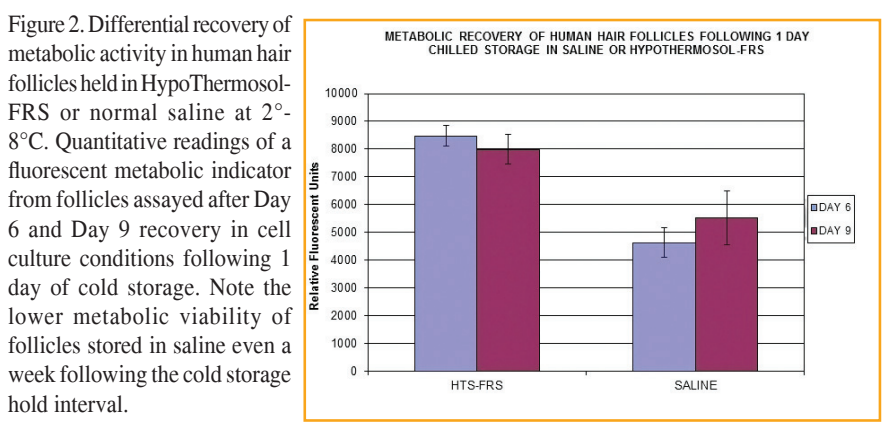




\section{Graft Holding Temperature}

A number of discussions within the hair transplant arena have also focused on the appropriate strip/graft holding temperature. Some have reported adequate graft recovery following ambient storage, ${ }^{33,35,36}$ some have advocated using a temperature that straddles the fine line between freezing temperatures and nonfreezing temperatures $\left(0^{\circ} \mathrm{C}\right),{ }^{62}$ and many methods utilize the chilling temperature of $4^{\circ} \mathrm{C} .{ }^{32,33,63,64} \mathrm{It}$ is of noted interest that positive graft survival results have resulted from a wide range of temperature $\left(0^{\circ} \mathrm{C}\right.$ to ambient $)$, however, there is certainly variability in the interpretation of graft "quality" within the hair transplant arena. As mentioned above, hypothermic temperatures offer the advantage of reducing metabolic degradation and reducing stress related to hypoxia/ischemia, similarly to that demonstrated in the organ preservation field. Beehner also reported a reduction in blunt trauma of the follicles associated with hypothermic temperatures. ${ }^{65}$ This is logical as the use of hypothermia likely limited the cumulative stresses occurring in grafts. Due to the difficulty in realistically maintaining an exact temperature under various conditions of hold or transport, industry cGMP (US FDA Current Good Manufacturing Practices) cold management tends to utilize the range of $2^{\circ}-8^{\circ} \mathrm{C}$ with a target point set as $4^{\circ} \mathrm{C}$ when referring to hypothermic preservation of cells and tissues. The concept of utilizing $0^{\circ} \mathrm{C}$ is certainly within logical reason if one appreciates the use of hypothermia to suppress metabolism. There are two considerations when dealing with $0^{\circ} \mathrm{C}$ as a target for cold storage. First, the reason that $4^{\circ} \mathrm{C}$ is considered "optimal" for hypothermic preservation of cells is because water has its maximum density of $1 \mathrm{~g} / \mathrm{cm}^{3}$ at $4^{\circ} \mathrm{C}$, which then may affect osmotic fluctuations. Secondly, $0^{\circ} \mathrm{C}$ has the potential for ice crystal formation if temperature fluctuates below $0^{\circ} \mathrm{C}$. Metabolically, $0^{\circ} \mathrm{C}$ will slightly lower the metabolism compared to $4^{\circ} \mathrm{C}$ but not by much (comparative range of $5 \%$ vs. $3.75 \%$ of normothermic metabolism), and it could be argued that the increased risk of slight temperature fluctuations below freezing that could cause damaging ice crystals may not be worth the risk.

\section{ATP within Hair Transplantation}

Recently, there has been growing interest in and reports of the utilization of ATP (adenosine triphosphate) as part of hair transplant procedures. This is an avenue of logical targeted intervention, as some of the damaging effects of ischemia/hypoxia are based on the inability to support maintenance of cellular energy. However, it should be noted that not all forms of delivering ATP to the cell are equivalent in efficacy. The ATP molecule itself is only capable of relatively short stability, especially during preservation. Therefore, effectively delivering ATP to the cell is also due consideration. Cooley ${ }^{66}$ and Beehner ${ }^{67}$ have reported promising results from longterm cold storage of grafts that were maintained in the combination of an intracellular-like preservation solution (HypoThermosolFRS) and a liposomal embodiment of ATP. The novel liposomal ATP is based on Ehringer's work at the University of Louisville ${ }^{68}$ where the ATP is packaged within liposomes (lipid membranes) that are able to fuse with the cell's own bilipid membrane to efficiently deliver ATP into the cell. Further studies are warranted, however, this promising combination method brings together one method of reducing stress during graft storage (intracellular-like HypoThermosol media) with another method that targets a cellular deficiency during and after graft storage (effective delivery of ATP inside the cell). Cooley showed that in an enhanced stress model to highlight potential avenues for cellular preservation, grafts stored in saline resulted in $0 \%$ survival, and grafts stored in HypoThermosol-FRS demonstrated $44 \%$ survival. ${ }^{66}$ This comparison alone highlights the benefits of improved biopreservation using an intracellular-like holding solution. Furthermore within this same single-patient study, Cooley reported that grafts stored in the combination of HypoThermosol-FRS and liposomal ATP exhibited $72 \%$ survival. Figure 3 highlights the visual results reported by Cooley in this single-patient study for the HypoThermosol®FRS + liposomal ATP sample set.

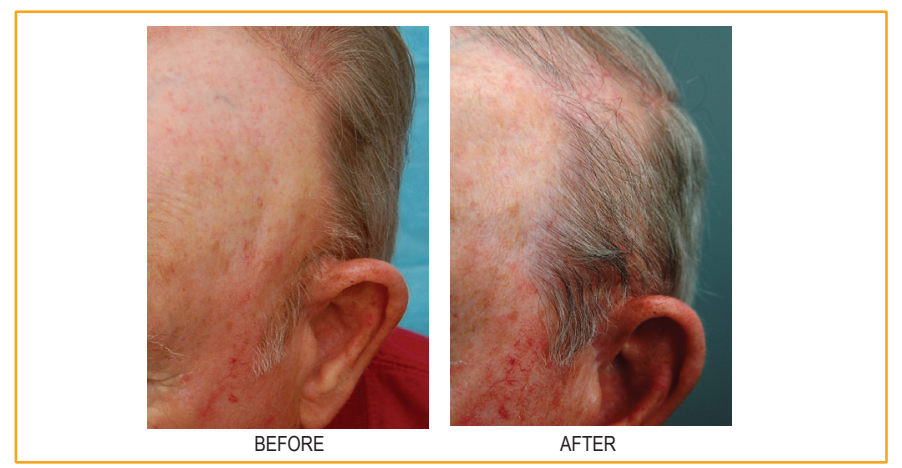

Figure 3. Efficacy of hair follicle transplant following 5 days of storage at $4{ }^{\circ} \mathrm{C}$ in HypoThermosol + liposomal ATP. A single patient study was undertaken in a 71-year-old man, who had both male pattern hair loss and a large area of alopecia on the left temple as a result of radiation for skin cancer. Donor hair was harvested from the occipital scalp, dissected, and stored for 5 days at $4^{\circ} \mathrm{C}$. Afterwards, grafts were implanted into alopecic areas (1,200 grafts). The patient was seen at 3,6, and 9 months for evaluation and final hair counts were performed at 12 months.

\section{Further Summary Considerations}

Hair transplant physicians operate under the practice of medicine with appreciable flexibility within their clinical methods. Hair transplant physicians can also appreciate an aspect of what they do as a form of regenerative treatment for the patient (with each ISHRS Annual Meeting there also seems to be increased profile of the cell-based hair regenerative medicine treatments from groups such as Intercytex, Aderans, RepliCel, etc.). Within the regenerative medicine field (cell therapy and tissue engineering), regulatory agencies provide guidance for the use of current Good Manufacturing Practices (cGMP). One aspect that is advised within cGMP is risk management, where assessment and mitigation of potential system risks is mandated to ensure appropriate quality of the manufactured end therapeutic product. Similarly, within a hair transplant procedure, one inherent goal is to maximize the quality of the transplant (graft survival, hairline design, graft density, scalp irritation/edema, rate of regrowth, hair shaft thickness, etc.). As mentioned above, there are multiple points of stress within a procedure that could affect the transplant quality and there are a variety of holding/storage solutions utilized for in-process graft holding. This one step in the transplantation procedure is worth further examination to assess whether clinical practice and current methods are aligned with cGMP guidance for risk mitigation and management. Again, the improved biopreservation protocol of using an intracellular-like solution has been qualified by a number of regenerative medicine therapies including cardiac applications, ${ }^{57-58}$ stem cell applications, ${ }^{59}$ and dermal fibroblast applications. ${ }^{60}$

As noted by Parsley and Perez-Meza, there may be some discrepancy between the often-reported high graft survival rates and the overall actual percentage of graft survival across the variable patient pool. ${ }^{33}$ In the best examples used of patients with $>90 \%$ graft survival, there may be limited room for perceived or actual improvement. However, there are several considerations to weigh. If the patients who do not enter the procedure with the 
Cellular biopreservation

from page 9

best quality scalp, donor tissue, and health have the potential to bring pre-existing stresses into the procedure even before the first extraction, there is the strong possibility that the further stresses outlined above during the procedure may result in cumulative stresses that compromise the quality of the transplant. Even with rigorous patient screening, it may be difficult to fully know the variable preconditions (intangibles) a patient brings into the procedure that might negatively impact the quality of the transplant. Therefore, any potential stress mitigation steps (such as improved holding solutions) may reduce the likelihood of an unsatisfied patient. The strip/graft holding steps of the hair transplantation procedure are of critical importance to the success of the hair transplant. This review highlights much information that has been accumulated regarding cell, tissue, and organ biopreservation, with many topics still for further scientific examination. The lessons from organ transplant and regenerative medicine offer insight toward methods of using optimized intracellular-like hypothermic storage media for improved graft ex vivo preservation as one step in continuously maximizing patient outcomes.

\section{References}

1. Baust, J.G. In: J.G. Baust and J.M. Baust, eds. Advances in Biopreservation. CRC Press, 2007; 1-14.

2. Snyder, K.K., et al. Biological packaging for the global cell and tissue therapy markets. BioProcessing Journal. 2004(May/June); 1-7.

3. Reyes, A.B., J.S. Pendergast, and S. Yamazaki. Mammalian peripheral circadian oscillators are temperature compensated. J Biol Rhythms. 2008; 23:95-98.

4. Allen, F.M. Physical and toxic factors in shock. Archives of Surgery. 1939; 38:155-180.

5. Bigelow, W.G., W.K. Lindsay, and W.F. Greenwood. Hypothermia: its possible role in cardiac surgery: an investigation of factors governing survival in dogs at low body temperature. Annals of Surgery. 1950; 132:849-866.

6. Swan, H., et al. Hypothermia in surgery: analysis of 100 clinical cases. Annals of Surgery. 1955; 142:382-400.

7. Collins, G.M., M. Bravo-Shugarman, and Pl. Terasaki. Kidney preservation for transplantation: initial perfusion and 30 hours ice storage. Lancet. 1969; 2:1219.

8. Taylor, M.J., et al. A new solution for life without blood: asanguineous low flow perfusion of a whole-body perfusate during 3 hours of cardiac arrest and profound hypothermia. Circulation. 1995; 91:431-444.

9. Van Buskirk, R.G., et al. Assessment of hypothermic storage of normal human epidermal keratinocytes (NHEK) using Alamar Blue. In Vitro Toxicology. 1996; 9:297-303.

10. Mathew, A.J., J.G. Baust, and R.G. Van Buskirk. Optimization of HypoThermosol for the hypothermic storage of cardiac cells—addition of EDTA. In Vitro Toxicology. 1997; 10(4):407-415.

11. Mathew, A.J., et al. Vitamin E and EDTA improve the efficacy of HypoThermosol-implication of apoptosis. In Vitro Toxicology. 1999; 12(3):163-172.

12. Dahdah, N.S., et al. Effects of HypoThermosol, an experimental acellular solution for tissue preservation and cardiopulmonary bypass, on isolated newborn lamb coronary vessels subjected to ultraprofound hypothermia and anoxia. Cryobiology. 1999; 39:58-68.
13. Mathew, A.J., J.G. Baust, and R.G. Van Buskirk. Improved hypothermic preservation of human renal cells through suppression of both apoptosis and necrosis. Cell Preservation Technology. 2003; 1:239-254.

14. Baust, J.M., et al. Transplantation diagnostics: utilization of protein microarray analysis to determine kidney status and transplantation efficacy. Cell Preservation Technology. 2004; 2(2):81.

15. Mathew, A.J., et al. Cell preservation in reparative and regenerative medicine: evolution of individualized solution composition. Tissue Engineering. 2004; 10:1662-1671.

16. Snyder, K.K., et al. Biological packaging for the global cell and tissue therapy markets. BioProcessing Journal. 2004; 3(3):39.

17. Van Buskirk, R.G., et al. Hypothermic storage and cryopreservation: the issues of successful short-term and long term preservation of cells and tissues. BioProcess Int'l. 2004; 2(10):42.

18. Baust, J.M. Advances in media for cryopreservation and storage. BioProcess International. 2005; 3:46-56.

19. Snyder, K.K., et al. Enhanced hypothermic storage of neonatal cardiomyocytes. Cell Preservation Technology. 2005; 3(1):61-74.

20. Mathew, A.J. I'm losing cell viability and function at different points in my process, and I don't know why! BioProcess Int'l. 2010; 8(6) 54-7.

21. Ikonomovic, M., et al. Ultraprofound cerebral hypothermia and blood substitution with an acellular synthetic solution maintains neuronal viability in rat hippocampus. CryoLetters. 2001; 22:19-26.

22. Lodish, H.F., et al. Transport across cell membranes. In: S. Tenney, ed. Molecular Cell Biology. 4th Edition. New York: W.H. Freeman, 2000; 590-591.

23. MacKnight, A.D.C., and A. Leaf. Regulation of cellular volume. Physiology Review. 1977; 57:510.

24. Martin, D.R., et al. Primary cause of unsuccessful liver and heart preservation: cold sensitivity of the ATPase system. Annals of Surgery. 1972; 175:11.

25. Boutilier, R.G. Mechanisms of cell survival in hypoxia and hypothermia. J of Experimental Biology. 2001; 204:31713181.

26. Toledo-Pereyra, L.H., A.J. Paez-Rollys, and J.M. PalmaVargas. Science of organ preservation. In: L.H. ToledoPereyra, ed. Organ Procurement and Preservation for Transplantation. Landes Bioscience, 1997; 1-16.

27. Rehncrona, S., B.K. Siesjo, and D.S. Smith. Reversible ischemia of the brain: biochemical factors influencing restitution. ActaPhysioliogy Scandinavia. 1979; Suppl 492:135.

28. Cotterill, P. ISHRS survey majority using chilled saline. W. Reed Personal communication, December 2012.

29. Reed, W. Personal communication, December 2012.

30. Perez-Meza, D., M. Leavitt, and M. Mayer. The growth factors. Part 1: clinical and histological evaluation of the wound healing and revascularization of the hair graft after hair transplant surgery. Hair Transplant Forum Int'l. 2007; 17(5):173.

31. Perez-Meza D. Wound healing and revascularization of the hair transplant graft: role of the growth factors. In: W. Unger and R. Shapiro, eds. Hair Transplantation, 4th Ed. Marcel Dekker, New York, 2004; 287-294.

32. Cooley, J. Ischemia-reperfusion injury and graft storage solutions. Hair Transplant Forum Int'l. 2004; 14(4):121,127,130. 
33. Parsley, W.M., and D. Perez-Meza. Review of factors affecting the growth and survival of follicular grafts. J Cutan Aesthet Surg. 2010; 3(2):69-75.

34. Limmer, R. Micrograft survival. In: D. Stough, ed. Hair Replacement. Mosby Press, 1996; 147-149.

35. Kim, J.C., and S. Hwang. The effects of dehydration, preservation temperature and time, and hydrogen peroxide on hair grafts. In: W.P. Unger and R. Shapiro, eds. Hair Transplantation, 4th Ed. New York: Marcel Dekker, 2004; 285-286.

36. Hwang, S.J., et al. The effects of dehydration, preservation temperature and time on the hair grafts. Annals of Dermatology. 2002; 14:149-152.

37. Krugluger, W., et al. Enhancement of in vitro hair shaft elongation in follicles stored in buffers that prevent follicle cell apoptosis. Dermatol Surg. 2004; 30:1-5.

38. Krugluger, W., et al. New storage buffers for micrografts enhance graft survival and clinical outcome in hair restoration surgery. Hair Transplant Forum Int'l. 2003; 13(3):333334.

39. Van Buskirk, R.G., et al. Navigating the post-preservation viability fog: assay standardization for cell and tissue therapy applications. Genetic Engineering News. 2006; 26(19):38-39.

40. Van Buskirk, R. Viability and functional assays used to assess preservation efficacy: the multiple endpoint/tier approach. In: J.G. Baust and J.M. Baust, eds. Advances in Biopreservation. CRC Press-Taylor and Francis Publishing: New York, 2006.

41. Belzer, F., and J. Southard. Principles of solid-organ preservation by cold storage. Transplantation. 1988; 45(4):673676.

42. Taylor, M.J. The role of $\mathrm{pH}$ and buffer capacity in the recovery of function of smooth muscle cooled to $-13^{\circ} \mathrm{C}$ in unfrozen media. Cryobiology. 1982; 19:585-60.

43. Taylor, M.J., and Y. Pignat. Practical acid dissociation constants, temperature coefficients and buffer capacities for some biological buffers in solutions containing dimethyl sulfoxide between 25 and $-12^{\circ}$ C. Cryobiology. 1982; 19:99109.

44. Fujita, J. Cold shock response in mammalian cells. J Mol Microbiol Biotechnol. 1999; 1(2):243-255.

45. Plesnila, N., et al. Effect of hypothermia on the volume of rat glial cells. Journal of Physiology. 2000; 523.1:155-162.

46. Tseng, Y-C, et al. Exploring uncoupling proteins and antioxidant mechanisms under acute cold exposure in brains of fish. PLoS ONE. 2011; 6(3):1-15.

47. Corwin, W.L., et al. The unfolded protein response in human corneal endothelial cells following hypothermic storage: Implications of a novel stress pathway. Cryobiology. 2011; 63(1):46-55.

48. Baust, J.M. Overview of hypothermic storage. Hair Transplant Forum Int'l. 2006; 16(2):53.

49. Cosentino, L.M., et al. Preliminary report: evaluation of storage conditions and cryococktails during peripheral blood mononuclear cell cryopreservation. Cell Preservation Technology. 2007; 5:189-204.

50. Baust, J.M., R.G. Van Buskirk, and J.G. Baust. Cell viability improves following inhibition of cryopreservation-induced apoptosis. In Vitro Cell and Developmental Biology. 2000; 36:262.

51. Baust, J.M., et al. A molecular basis of cryopreservation failure and its modulation to improve cell survival. Cell Transplantation. 2001; 10:561.
52. Baust, J.M., R.G. Van Buskirk, and J.G. Baust. Gene activation of the apoptotic caspase cascade following cryogenic storage. Cell Preservation Technology. 2002; 1:63.

53. Baust, J.M. Molecular mechanisms of cellular demise associated with cryopreservation failure. Cell Preservation Technology. 2002; 1:17.

54. Anderson, R.V., M.G. Siegman, and R.S. Balaban. Hyperglycemia increases cerebral intracellular acidosis during circulatory arrest. Annals of Thoracic Surgery. 1992; 54:1126-1130.

55. Ely, S.W., and R.M. Berne. Protective effects of adenosine in myocardial ischemia. Circulation. 1992; 85:893-904.

56. Bessems, M., et al. Preservation of rat livers by cold storage: a comparison between the University of Wisconsin solution and HypoThermosol. Ann Transplant. 2004; 9(2):35-37.

57. Povsic, T., et al. A double-blind, randomized, controlled, multicenter study to assess the safety and cardiovascular effects of skeletal myoblast implantation by catheter delivery in patients with chronic heart failure after myocardial infarction. American Heart Journal. 2011; 162(4):654-662.

58. Powell, R., et al. Interim analysis results from the RESTORE-CLI, a randomized, double-blind multicenter phase II trial comparing expanded autologous bone marrow-derived tissue repair cells and placebo in patients with critical limb ischemia. J of Vasc Surg. 2011; 54(4):1032-1041.

59. Ginis, I., B. Grinblat, and M. Shirvan. Evaluation of bone marrow-derived mesenchymal stem cells after cryopreservation and hypothermic storage in clinically safe medium. Tissue Engineering Part C Methods. 2012; 18(6):453-463.

60. Lowe, N.J., P.L. Lowe, and J. St Clair Roberts. A phase IIa open-label dose-escalation pilot study using allogeneic human dermal fibroblasts for nasolabial folds. Dermatol Surg. 2010; 36(10):1578-1585.

61. Raposio, E., et al. Effects of cooling micrografts in hair transplantation surgery. Dermatol Surg. 1999; 25:705-707.

62. Jiange, Q., et al. How long can hair follicle units be preserved at 0 and $4^{\circ} \mathrm{C}$ for delayed transplant? Dermatol Surg. 2005; 31:23-26.

63. Cole, J.P. The optimal holding solution and temperature for hair follicle. http://www.forhair.com/Articles/The_optimal_holding_solution_and_temperature_for_hair_follicle. htm.

64. Kurata, S., et al. Viability of isolated single hair follicles preserved at $4^{\circ}$ C. Dermatol Surg. 1999; 25:26-29.

65. Beehner, M.L. Notes from the Editor Emeritus. Hair Transplant Forum Int'l. 2005; 15(6):193-195.

66. Cooley, J.E. Successful extended storage of hair follicles using hypothermic media with liposomal ATP. Translational Regenerative Medicine Forum. 2010.

67. Beehner, M.L. 96-hour study of FU graft "out-of-body" survival comparing saline to HypoThermosol/ATP solution. Hair Transplant Forum Int'l. 2011; 21(2):1, 37.

68. Ehringer, W.D. New horizons in storage solutions and additive agents in organ transplantation. Norwood Lecture, ISHRS 2011 Annual Scientific Meeting. 